\title{
Recording of particles velocity spectrum at the shock impact on different viscosity interface of liquids
}

\author{
A.V. Fedorova ${ }^{a}$, A.L. Mikhailov, S.A. Finyushin, D.A. Kalashnikov, E.A. Chudakov, E.I. Butusov, and I.S. Gnutov \\ RFNC-VNIIEF, Nizhniy Novgorod reg., Sarov, Russia
}

\begin{abstract}
The results of experiments concerning the study of cavitational mechanism of liquid failure in a wide range of shock loading are presented in this paper. Free surface velocity of liquids and velocity spectrum of particles and jets were recorded using PDV method [1], their size was also determined. The value of spall strength of distilled water was defined.
\end{abstract}

\section{Introduction}

There are several mechanisms of shock ejecting: particle ejecting from the rough surface, spall fragmentation of material induced by internal tensile stresses, microcumulative jets appearing on gas bubbles, inhomogeneity of material structure etc. [2-5]. The case in study of shock ejecting in liquids and liquid metals with smooth and mirror-like surfaces is of special interest. In this case, there is no particle ejecting owing to the surface roughness.

The main goal of this paper is to study the dynamics of the drop cloud formation and to record the particle velocity spectrum as a result of cavitational damage of liquids which values of viscosity can differ in thousand times.

\section{Experimental setup}

Liquids with different values of viscosity (distilled water - 0.89 centipoise; ethanol - 1.07 centipoise; glycerin 934 centipoise; oil VM1 - 300 centipoise) were chosen for experiments.

Liquids $(\varnothing 80 \mathrm{~mm})$ were loaded up to high $(\mathrm{P}=7-$ $11 \mathrm{GPa})$ and low $(\mathrm{P}=0.1-0.9 \mathrm{GPa})$ pressures. In the first case, liquids were loaded by plane stationary shock wave (SW) from $\mathrm{HE}(\varnothing 120 \times 40 \mathrm{~mm})$ through an aluminum disk $(\varnothing 120 \times 1 \mathrm{~mm})$, in the second case - by divergent wave with triangular section from explosion of detonator through an aluminum or steel disk $(\varnothing 120 \times 1 \mathrm{~mm})$. The thickness of liquid layer was varied in a range of 5-30 $\mathrm{mm}$. The velocities of the particles and the free surface (FS) were recorded using laser heterodyne-interferometer (PDV method). The PDV probe was placed at a distance of 35$50 \mathrm{~mm}$ from the surface.

\section{Experimental results}

Experimental results are shown in Table 1: $\mathrm{W}_{\mathrm{FS}}, \mathrm{P}_{\mathrm{SW}}$-the free surface velocity and shock pressure in liquids, $\mathrm{V}_{\mathrm{FF}}^{\mathrm{max}}-$ maximum velocity of the particle flow front at the moment of SW arrival to the free surface.

\footnotetext{
${ }^{a}$ Corresponding author: Fedorovsarov@mail .ru
}

\subsection{Recording of particle velocity spectrum under loading of liquid up to high pressures}

Experimental velocity spectrogram of ethanol drops (test \#2) is shown in Fig. 1. The similar spectrograms are obtained for water, glycerin and oil. The PDV method allows to record the free surface velocity, the moments of shock impact and the flight time of liquid free surface and flow front (FF) to a collimator. Using the known base length, $\mathrm{W}_{\mathrm{FS}}$ and the average flight velocity of drops, $\mathrm{V}_{\mathrm{FF}}$ can be determined. The average velocity $\mathrm{V}_{\mathrm{FF}}$ for three liquids was equal to $4.6-5.0 \mathrm{~km} / \mathrm{s}$. The average velocity $\mathrm{V}_{\mathrm{FF}}$ for ethanol was equal to $5.6 \mathrm{~km} / \mathrm{s}$. High initial velocities of ejecting liquid particles $\mathrm{V}_{\mathrm{FF}}^{\max }$ $(4.9-5.9 \mathrm{~km} / \mathrm{s})$ are recorded in spectrograms of the first four tests. According to particle braking law in the air at such high velocities, the particles must have high gradient of velocity decay what can be seen in the initial time. The process of particle size determination using their braking curves in gas is described in [6]. Spectrogram and deceleration pattern droplets for ethanol are shown in Fig. 1. Under hard braking of particles in gas, an air shock wave (ASW) runs rapidly and the particles get into the region of the air compressed by SW ( $\mathrm{P}=330$ bar) where gas velocity must be equal to the piston velocity $\mathrm{W}_{\mathrm{FS}}=4.98 \mathrm{~km} / \mathrm{s}$.

But the free surface velocity is $6 \%$ lower than $\mathrm{U}_{\text {air }}=$ $5.27 \mathrm{~km} / \mathrm{s}$. The excess of the air velocity over SF velocity is connected, in our opinion, with the fact that the cloud of liquid drops has high values of density and velocity, and it additionally speeds up the air and increases its velocity in $\approx 6 \%$.

According to the flight time of particle flow front and the free surface of liquid to collimator, the particle cloud thickness can be determined. The cloud thickness for liquids (ethanol, water, glycerin, oil) is $5 \mathrm{~mm}$, $4 \mathrm{~mm}, 4.5 \mathrm{~mm}$ and $5.4 \mathrm{~mm}$, correspondingly. The excess of maximum particles front velocity over free surface velocity in tests was equal to 25-35\%. The free surface velocity $\mathrm{W}_{\mathrm{FS}}$ cannot be recorded by PDV method in real experiments. It is connected with high density of ejecting particles, as laser beam is not able to illuminate.

This is an Open Access article distributed under the terms of the Creative Commons Attribution License 4.0, which permits unrestricted use, distribution, and reproduction in any medium, provided the original work is properly cited. 
Table 1. Experimental results.

\begin{tabular}{|c|c|c|c|c|c|}
\hline \# & Liquid & $\begin{array}{l}\begin{array}{l}\text { Liquid } \\
\text { thick- } \\
\text { ness }\end{array} \\
\Delta \text {, } \\
\text { mm }\end{array}$ & $\mathbf{P}_{\mathrm{SW}}, \mathbf{G P a}$ & $\begin{array}{l}W_{\mathrm{FS}} \\
\mathrm{km} / \mathrm{s}\end{array}$ & $\begin{array}{c}\mathbf{V}_{\mathbf{F F}}^{\max }, \\
\mathbf{k m} / \mathbf{s}\end{array}$ \\
\hline 1 & Water & 12 & 10.3 & 4.44 & 5.03 \\
\hline 2 & Ethanol & 12 & 9.7 & 4.98 & 5.9 \\
\hline 3 & Glycerin & 12 & 10.7 & 4.07 & 5.02 \\
\hline 4 & Oil & 12 & 7.3 & 4.08 & 4.95 \\
\hline 5 & Water & 20 & 0.18 & 0.195 & 0.25 \\
\hline 6 & Water & 5 & 0.86 & 0.76 & 0.78 \\
\hline 7 & Water & 10 & 0.093 & 0.11 & 0.3 \\
\hline 8 & Glycerin & 30 & 0.22 & 0.17 & - \\
\hline 9 & Glycerin & 20 & 0.35 & 0.26 & 0.25 \\
\hline
\end{tabular}

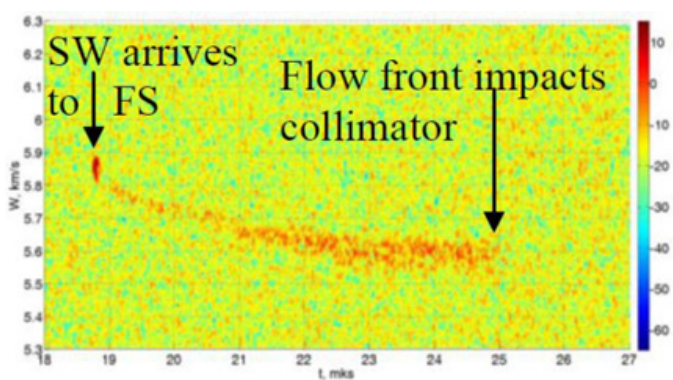

$\mathrm{P}=1$ bar

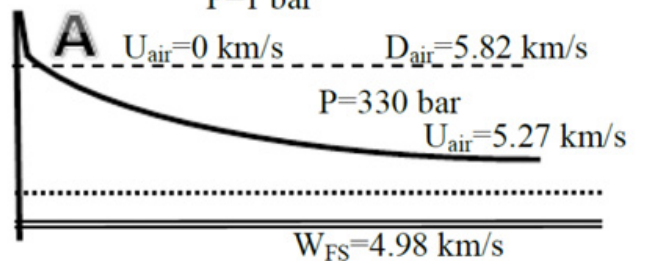

Figure 1. Spectrogram and deceleration pattern droplets for ethanol in the air.

Mechanism of dense drop cloud formation at the moment of SW arrival to FS of liquids is described in [5]. It is shown there that cavitational clusters grow in a tensile stress field and the liquid is gradually transiting into a singular foam phase in a form of thin films or a net of liquid bundles. Liquid net elements under further tension are divided into separate fragments and after that into jets which are failed into separate drops under effect of instability and surface tension.

\subsection{Recording of particle velocity spectrum under loading up to low pressures}

Three tests (\#5, \#6, \#7) with water (see Fig. 2, spectrograms of the tests \#5 and \#7 are similar) and two tests (\#8, \#9) with glycerin (see Fig. 3) were conducted with loading up to low pressures $(\mathrm{P} \approx 0.1-0.9 \mathrm{GPa})$. A divergent wave with triangular section propagates from detonator, and it intensively decays when passing through a liquid. The free surface velocity is recorded in the tests \#5 and \#7. A dense layer of liquid particles blocks laser emission in the test \#6. Velocity tracks were recorded in spectrograms of the tests \#5 and \#7 after SW arrival to the free surface.
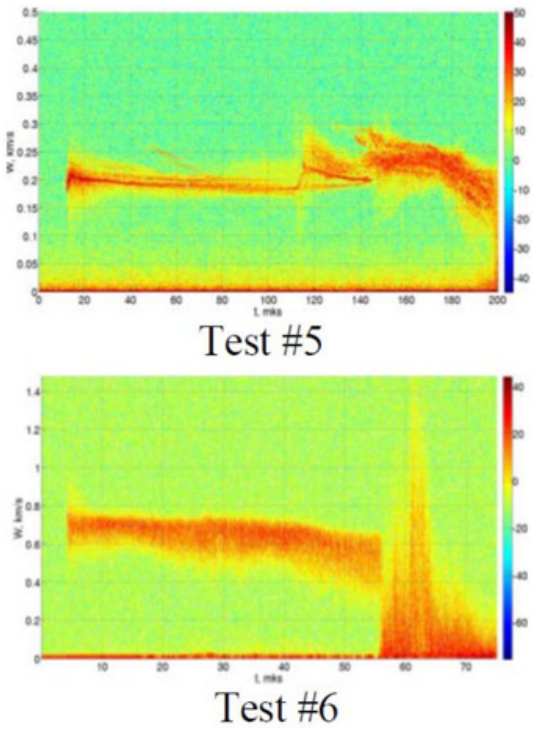

Figure 2. Spectrograms of the tests with water.

According to these tracks, the size of drops and jets was equal to 7-19 $\mu \mathrm{m}$ in the test \#5 and 5-25 $\mu \mathrm{m}$ in the test \#7 (see Fig. 2 and Fig. 4).

Drop size in these tests was determined taking into account gas compression after ASW passing, i.e., the drops move inside so called "air cushion". Cavitational failure of water is recorded in the test \#6, and a cloud of drops moving with the maximum front velocity of $0.68 \mathrm{~km} / \mathrm{s}$ and dispersion of the cloud velocity of $\approx 120 \mathrm{~m} / \mathrm{s}$ is seen in a spectrogram. High velocity of the drop cloud if compared with the other tests is caused by higher decay gradient and shock parameters. It should be noticed that such failure pattern is observed in all the tests with water under the pressure of $\mathrm{P}>0.2-0.3 \mathrm{GPa}$. The spall pulse is clearly seen in the tests with water at the moment of SW arrival to the free surface. The value of spall strength of water was equal to $\sigma=30 \mathrm{MPa}$, the thickness of the first spall layer was $0.1-0.25 \mathrm{~mm}$ in different tests.

The velocities of three spall layers are recorded by PDV in spectrogram of the test \#5 (W $=0.19 \mathrm{~km} / \mathrm{s}$, $\mathrm{W}=0.199 \mathrm{~km} / \mathrm{s}$ and $\mathrm{W}=0.206 \mathrm{~km} / \mathrm{s}$ ), the surfaces of these layers reflect laser emission. Moving spall layers during $\Delta \mathrm{t}=80 \mu \mathrm{s}$ pass $15.2 \mathrm{~mm}, 16 \mathrm{~mm}$ and $16.8 \mathrm{~mm}$, correspondingly. At $\mathrm{t}=80-100 \mu \mathrm{s}$ it is seen that laser beam starts to be reflected not from the free surface of spall layers but from the cloud of particles. I.e., fragmentation of these spall layers into drops occurs under effect of the forces of surface tension and instabilities of boundaries.

The results of the tests with glycerin are shown in Fig. 3. Velocity tracks of the drops and jets of glycerin are clearly seen in spectrogram of the test \#9. The absence of tracks in the test \#8 is a subject of further research. It is seen in spectrogram of the test \#9 that there are two regions: the region of front moving jets and the region of cavitating liquid. In this case, the front of cavitating liquid moves at $6.6 \mathrm{~mm}$ in the first $30 \mu$ s of motion and the front of the slowest jets moves at $7.8 \mathrm{~mm}$. I.e., the jets tear away $1.2 \mathrm{~mm}$ from the main mass of liquid. The front of faster jets tears away further. 


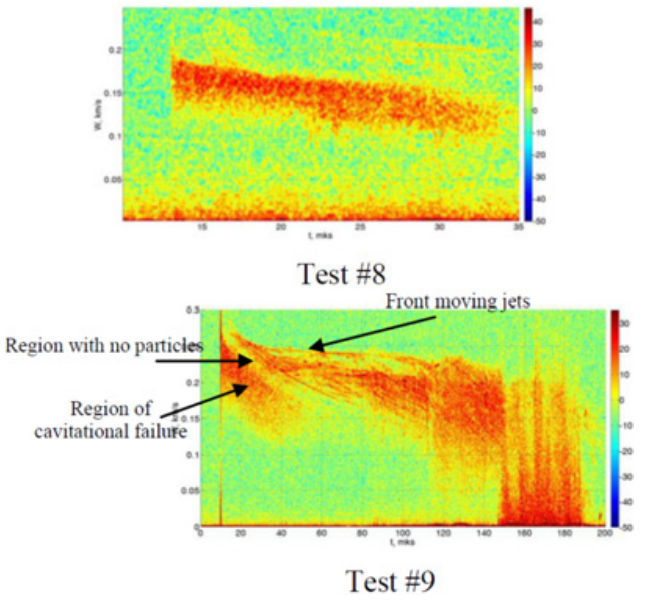

Figure 3. Spectrograms of the tests with glycerine.

Thus, the region with the velocity dispersion of $\approx 30 \mathrm{~m} / \mathrm{s}$ is recorded by PDV (see "region with no particles" in Fig. 3). The size of fine drops in the test \#9 was equal to $28-80 \mu \mathrm{m}$ (see Fig. 4). The tracks corresponding to large-scale jets with the size of 200$550 \mu \mathrm{m}$ are seen as well. The bigger (if compared with water) size of glycerin jets is probably connected with the higher value of liquid viscosity.

Spectrograms of the tests with water and glycerin are presented in Fig. 4. Particle tracks are shown by black lines. The proof of jet mechanism of liquid ejecting is an estimation of front displacement of the fastest jets. The maximum velocity of $0.25 \mathrm{~mm} / \mu$ s is recorded for jets with the characteristic size of $500 \mu \mathrm{m}$. Then these jets pass $25 \mathrm{~mm}$ at the moving interval of $100 \mu \mathrm{s}$. The average velocity of caviting liquid front does not exceed $0.18 \mathrm{~km} / \mathrm{s}$, i.e., it is equal to $18 \mathrm{~mm}$ at the moving interval of $100 \mu \mathrm{s}$. Thus, the large-scale jets will tear away $7 \mathrm{~mm}$ from the particle cloud. This effect was also recorded in [2] where the results of similar experiments conducted using the shadow optical technique are presented. The jet size in similar tests in [2] with glycerin was in a range from $100 \mu \mathrm{m}$ to $1 \mathrm{~mm}$, in tests with water it was equal to 7$19 \mu \mathrm{m}$. These values practically agree with our results. Thin jets of water moving in gas break up into drops, and glycerin jets do not break up.

\section{Discussion}

It is known that the average size of gas bubbles for water is of $\mathrm{d} \approx 1.5 \mu \mathrm{m}$ [5], and cumulative jets formed in bubbles at the moment of SW arrival to FS are not able to break through the water layer bordered on the surface (the ejecting process is not recorded in spectrogram at the beginning of the record). The bubble size of viscous glycerin is of $\mathrm{d}=30-550 \mu \mathrm{m}$, and the ejecting is recorded just at the moment of SW arrival to FS. Thus, different ejecting mechanisms are realized in glycerin and water. The ejecting of microjets in glycerin occurs from the gas bubbles bordered on the liquid surface. At first, the free surface of water is mirror-like and there is no ejecting. After the wave reverberation in the first spall layer, the surface becomes rough, and the ejecting occurs when the following compression waves go out of it.

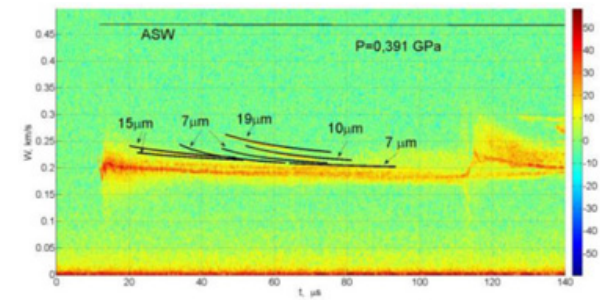

Test \#5

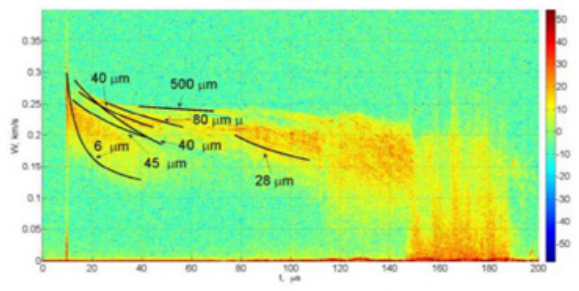

Test \#9

Figure 4. Spectrograms of the tests with water and glycerin.

\section{Conclusions}

The experiments with PDV recoding of particle ejecting from the surfaces of liquids with different viscosity in a wide range of loading pressures were conducted. It is shown that cavitational failure of liquids occurs under effect of tensile stresses. The spectra of liquid particle velocity and the velocity tracks of jets and drops are recorded, their size is determined. The size of jets is equal to 5-25 $\mu \mathrm{m}$ for water and 30-550 $\mu \mathrm{m}$ for glycerin. The difference in a particle size can be caused by significant difference in the viscosity values of glycerin and water. The spall strength of water is determined to be $\sigma=30 \mathrm{MPa}$.

\section{References}

[1] O.T. Strand, D.R. Goosman, C. Martinez, and T.L. Whitworth. Compact system for high-speed Velocimetry using heterodyne techniques. Rev. Sci. Instrum. 77. p. 083108-1-083108-8 (2006).

[2] N.V. Nevmerzhitskiy, E.A. Sotskov, E.D. Sen'kovskiy et al., Microscopic electron-optical recoding of particle ejecta from free surface of shock loaded metals and liquids. XV Khariton's topical scientific readings. Sarov (2013).

[3] V.M. Boiko and S.V. Poplavskii. Particle and Drop Dynamics in the Flow behind a Shock Wave. Fluid Dynamics. Vol. 42, \#3, pp.433-441 (2007).

[4] B.E. Gelfand. Droplet breakup phenomena in flows with velocity lag, Prog. Energy Combust. Sci. Vol. 22, pp. 201-265 (1996).

[5] V.K. Kedrinskiy. Hydrodynamics of explosion. Experiment and simulations. Novosibirsk (2000).

[6] A.V. Fedorov, A.L. Mikhailov, S.A. Finyushin, D.V. Nazarov, E.A. Chudakov, D.A. Kalashnikov, E.I. Butusov. Study of lead characteristic feature under shock loading and the following unloading. XV Khariton's topical scientific readings. Sarov. p. 274 (2013). 